\title{
Circuit analysis to predict humidity related failures in electronics - Methodology and
} recommendations

Joshy, Salil; Verdingovas, Vadimas; Jellesen, Morten Stendahl; Ambat, Rajan

Published in:

Microelectronics Reliability

Link to article, DOI:

10.1016/j.microrel.2018.12.010

Publication date:

2019

Document Version

Peer reviewed version

Link back to DTU Orbit

Citation (APA):

Joshy, S., Verdingovas, V., Jellesen, M. S., \& Ambat, R. (2019). Circuit analysis to predict humidity related failures in electronics - Methodology and recommendations. Microelectronics Reliability, 93, 81-88. https://doi.org/10.1016/j.microrel.2018.12.010

\section{General rights}

Copyright and moral rights for the publications made accessible in the public portal are retained by the authors and/or other copyright owners and it is a condition of accessing publications that users recognise and abide by the legal requirements associated with these rights.

- Users may download and print one copy of any publication from the public portal for the purpose of private study or research.

- You may not further distribute the material or use it for any profit-making activity or commercial gain

- You may freely distribute the URL identifying the publication in the public portal 


\title{
Circuit analysis to predict humidity related failures in electronics - Methodology and recommendations
}

\author{
Salil Joshy, Vadimas Verdingovas, Morten Jellesen, Rajan Ambat \\ Technical university of Denmark, Kgs. Lyngby, 2800, Denmark \\ saljos@mek.dtu.dk
}

\begin{abstract}
Aim of this paper is to demonstrate the use of circuit analysis to predict humidity robustness of an electronic circuit design. There is a lack of design tools which can predict failures due to humidity, especially the effect of humidity on electrical functionality of circuits. This work provides a methodology for utilising circuit simulation tools to detect humidity related faults associated with a circuit design by using experimentally determined leakage current data or surface insulation resistance using test pattern or model circuits. Simulation of circuits were performed with the experimentally determined SIR value as a parasitic resistance across two nodes of the circuit. Commonly used circuits such as a differential amplifier and a non-inverting comparator were analysed by this methodology. Based on the analysis, circuits with higher humidity robustness have been suggested as examples to demonstrate the effectiveness of this methodology. Finally, the correlation between the properties of the water layer on SIR pattern and actual components was done, which further demonstrates the applicability of the methodology.
\end{abstract}

KEY WORDS: Electronic circuit, humidity, contamination, surface insulation resistance, leak current.

\section{Introduction}

Electronic devices are used nowadays in variety of climatic conditions. Some of the applications are in controlled indoor climate, but others are exposed to harsh conditions like humid offshore locations, hot engine compartments of automobiles, atmospheres with corrosive gases etc. Application of electronics in harsh climates have shown failure modes due to high temperature[1][2], high humidity[3][4], gaseous corrosion[5][6], atmospheric contamination[7][8][9], and their combination. The failures due to humidity are aggravated by the recent drive towards miniaturisation and low-power consumption. Currently, robustness of electronic products to humidity is incorporated in the industry using prior knowledge of failures. There is a lack of simulation and analysis tools which can predict the effect of humidity and contamination on the electrical functionality of the circuit.

High humidity can accumulate inside electronic enclosures under both constant and cycling conditions of ambient temperature[10][11]. High humidity can also result from release of adsorbed and absorbed water from the walls of the enclosure[10]. Various mechanisms of humidity ingress into electronic enclosures is summarised by Jacobsen et.al.[14]. Presence of water vapour in the air can lead to formation of thin layer of water on a surface. The average number of monolayers of gas adsorbed on a surface is described by Brunauer-EmmettTeller (BET) theory[12]. Thickness of the water layer increases with increasing humidity and becomes visible under condensing conditions. Thick water layer containing dissolved ions on a Printed circuit board assembly(PCBA) leads to significant increase in leakage currents and failure modes such as electrochemical migration (ECM)[15][16][17][18].

A thicker layer of water could form on a PCBA surface even under non-condensing conditions in the presence of hygroscopic contamination. The PCBA manufacturing and component assembly process adds hygroscopic residues to the PCBA surface. Even no-clean solder fluxes used for component assembly leaves behind hygroscopic and ionic weakorganic acids (WOA) on the PCBA surface capable of causing significant leakage currents[19][20]. Commercially available solder flux systems commonly use WOAs as the activator component of the flux. WOAs like DL-malic acid present on PCBA can cause ECM failures even at RH of $80 \%[21][22]$.

The properties of water layer formed on a PCBA can be studied electrically by monitoring the leakage current or impedance of an SIR pattern[23][24]. The value of leak current could be monitored for different climatic conditions of RH and PCBA-surface contamination levels. This empirical data represents the behaviour of the water layer on a PCBA under different conditions of RH and WOA concentrations. Using this experimentally determined leakage-current data, the effect of formation of the water-layer and its electrical interference on the PCBA functionality can be modelled as a parasitic resistance[25]. This parasitic resistance could be included in analysis of a circuit using standard circuit simulation tools to predict the effect of humidity and contamination on its functionality. 
Circuit analysis to determine the effect of humidity and contamination on functionality of electronic circuits has been demonstrated in our earlier publications[25][26]. This paper has analysed more generic circuits using the above methodology and showed how the circuit modifications in such cases could improve the humidity robustness. The paper also evaluated the validity of using the leakage-current data from standard SIR patterns for this analysis. The circuits analysed in this paper for demonstration are a differential amplifier and a noninverting comparator. Leakage current data from SIR patterns contaminated with adipic acid and DL-malic acid, representing two extreme type no-clean solder flux residues from the point of view of aggressiveness are used for the analysis. Adipic acid is less corrosive because it has lower solubility in water and higher deliquescence RH (DRH) whereas, DL-Malic acid is highly soluble and has a lower DRH which makes it more corrosive. Sensitivity of both the differential amplifier and non-inverting comparator are compared for conditions in which the PCBA is made using adipic or DL-malic acid based no-clean flux and residues are remaining on the surface. Alternate circuit designs which are more tolerant to humidity-related failures are suggested which include an instrumentation amplifier and an inverting comparator. Also shown are design modifications like splitting of bigger resistances to multiple smaller resistances to make the circuits more robust to humidity. The experimentally determined data from SIR pattern is compared with that of land patterns of actual components with package dimensions 0402,0603 and 0805 to demonstrate the validity of using data from standard SIR patterns. PCBAs contaminated with succinic and glutaric acids are used for this comparison. Data from the actual components agree with the data from SIR pattern for both WOAs within an order of magnitude of leakage current.

\section{Extraction of SIR data for circuit analysis from humidity experiments}

The experimental data which describes the properties of water layer on PCBA comes from our earlier work[21]. The SIR patterns used were FR-4 PCBAs of size $13 \mathrm{~mm} \times 25 \mathrm{~mm}$ and pitch size of $0.3 \mathrm{~mm}$. The surface concentrations of WOAs on the SIR pattern used for the studies were $25 \mu \mathrm{g} / \mathrm{cm}^{2}, 50 \mu \mathrm{g} / \mathrm{cm}^{2}$ and $75 \mu \mathrm{g} / \mathrm{cm}^{2}$. Leakage current measurements were done with the SIR patterns placed in an ESPEC PL-3KPH climatic chamber at different levels of humidity and applied d.c voltage. Further details of the experiment design, methods and materials can be found else where[21][25].

The leakage current data from the experiments were converted to equivalent SIR for applied voltage of $5 \mathrm{~V}$. The SIR data thus obtained for adipic and DL-malic acids at various humidity levels are shown in tables 1 and 2.

\begin{tabular}{|c|r|r|r|}
\hline RH & $\begin{array}{r}\operatorname{SIR}(\mathrm{M} \Omega) \\
25 \mu \mathrm{g} / \mathrm{cm}^{2}\end{array}$ & $\begin{array}{r}\mathrm{SIR}(\mathrm{M} \Omega) \\
50 \mu \mathrm{g} / \mathrm{cm}^{2}\end{array}$ & $\begin{array}{r}\mathrm{SIR}(\mathrm{M} \Omega) \\
75 \mu \mathrm{g} / \mathrm{cm}^{2}\end{array}$ \\
\hline 60 & 5209.29 & 3090.5 & 2789.48 \\
\hline 70 & 4945.24 & 2157.70 & 1665.36 \\
\hline 80 & 2865.82 & 1204.58 & 922.45 \\
\hline 90 & 504.23 & 494.56 & 449.64 \\
\hline 95 & 209.69 & 263.49 & 293.21 \\
\hline 98 & 157.32 & 133.65 & 194.91 \\
\hline 99 & 102.78 & 45.73 & 23.79 \\
\hline
\end{tabular}

Table 1: SIR data for different values of $\mathrm{RH}$ and concentration of adipic acid at $25^{\circ} \mathrm{C}$ and d.c electrical input

\begin{tabular}{|c|r|r|r|}
\hline RH & $\begin{array}{r}\text { SIR(M } \Omega) \\
25 \mu \mathrm{g} / \mathrm{cm}^{2}\end{array}$ & $\begin{array}{r}\mathrm{SIR}(\mathrm{M} \Omega) \\
50 \mu \mathrm{g} / \mathrm{cm}^{2}\end{array}$ & $\begin{array}{r}\mathrm{SIR}(\mathrm{M} \Omega) \\
75 \mu \mathrm{g} / \mathrm{cm}^{2}\end{array}$ \\
\hline 60 & 2902.40 & 1634.53 & 602.40 \\
\hline 70 & 2587.40 & 303.69 & 39.93 \\
\hline 80 & 2071.03 & 21.12 & 3.18 \\
\hline 90 & 781.92 & 1.58 & 0.42 \\
\hline 95 & 151.02 & 0.65 & 0.32 \\
\hline 98 & 30.83 & 0.55 & 0.32 \\
\hline 99 & 6.62 & 0.52 & 0.28 \\
\hline
\end{tabular}

Table 2: SIR data for different values of RH and concentration of DL-Malic acid at $25^{\circ} \mathrm{C}$ and d.c electrical input

As seen from the data, SIR values drop with increasing values of RH and WOA surface concentrations for both adipic and DL-malic acid. The SIR drops drastically beyond the DRH of the WOA which is around 80\% for DL-malic acid and $98 \%$ for adipic acid. The decrease in resistance is more pronounced for SIR patterns contaminated with DL-malic acid as expected due to its higher solubility in water compared to adipic acid. The data in tables 1 and 2 are used for analysis of circuits in this paper. 
To correlate the leakage current data from SIR pattern with that on actual components, leakage current measurements were done on land patterns of surface-mount components placed on a test PCBA described elsewhere[27]. The WOAs used for this test were succinic acid and glutaric acid. The test PCBA contains land patterns for surface mount component sizes of 0402, 0603, 0805 and an SIR pattern on the same PCBA. The test PCBA was contaminated with WOA at the surface with a concentration of $100 \mu \mathrm{g} / \mathrm{cm}^{2}$. The test PCBA was placed in the ESPEC PL-3KPH environment chamber with required potential bias and subjected to different humidity profile as required. The leakage current across the component land-patterns and SIR pattern on the test PCBA were measured using a VSP Biologic potentiostat. The following section describes the comparison of leakage current data from SIR and components.

\section{Comparison of leak-current level from SIR and component testing}

Leakage currents were measured across surface-mount land-patterns of sizes 0402, 0603 and 0805 at a contamination surface concentration of $100 \mu \mathrm{g} / \mathrm{cm}^{2}$. Figures 1 and 2 show how the SIR values compare to resistances across actual components for succinic and glutaric acid respectively as contamination. Succinic acid and adipic acid has similar DRH of around $98 \%$. Glutaric acid has a lower DRH of around $83 \%$, near to that of Malic acid. Its solubility is also similar to that of DL-Malic acid of around $1400 \mathrm{~g} / \mathrm{L}$ of water at $25^{\circ} \mathrm{C}[21]$.

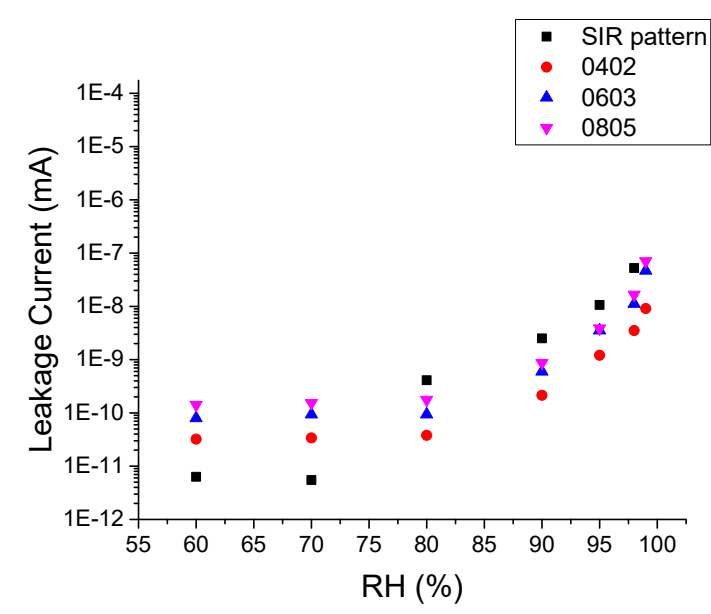

(a)

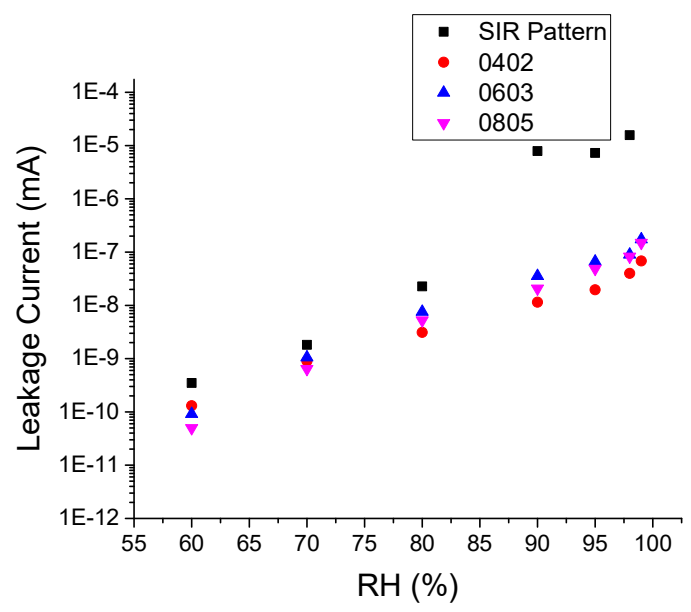

(b)

Figure 1: Comparison of leakage-current from SIR and actual components for a) Succinic acid b) Glutaric acid as contamination at $25^{\circ} \mathrm{C}$ and d.c electrical input.

For succinic acid it was seen that the leakage-current values for the SIR and land-patterns are within an order of magnitude of each other in the full range of RH as shown in figure 1a. For glutaric acid, the leakage current values for SIR pattern and land-patterns are also within an order of magnitude of each other until the DRH of glutaric acid of 83$89 \%$. Beyond the DRH of glutaric acid, the SIR pattern showed higher leakage current. For RH higher than DRH, the resistance of SIR pattern was two orders of magnitude lower compared to land-patterns as shown by figure $1 \mathrm{~b}$. So, the method of using resistance of water layer from SIR values for analysis with electronic circuits is a valid approximation for succinic acid in the entire range of RH upto $100 \%$. For Glutaric acid, the approximation is valid until DRH beyond which the accuracy of the SIR data degrades.

\section{Analysis of humidity robustness of circuits using electrochemical data}

Two types of circuits are used for analysis in this work: (i) a differential amplifier and (ii) a non-inverting comparator. The differential amplifier is a common circuit block used in analog electronics to amplify sensed pressure, strain, electric current etc. The circuit produces an output voltage which is a constant times the difference of the voltages at the two input terminals given by:

where, ' $G$ ' is the differential-gain of the amplifier.

$$
V \text { out }=G .\left(V \text { in }_{+}-V \text { in }_{-}\right)
$$

The gain ' $G$ ' is also given in terms of the resistances as 
if $\mathrm{R} 1=\mathrm{R} 4$ and $\mathrm{R} 2=\mathrm{R} 3$. Figure $2 \mathrm{a}$ shows the schematic of a differential amplifier of gain 10 .

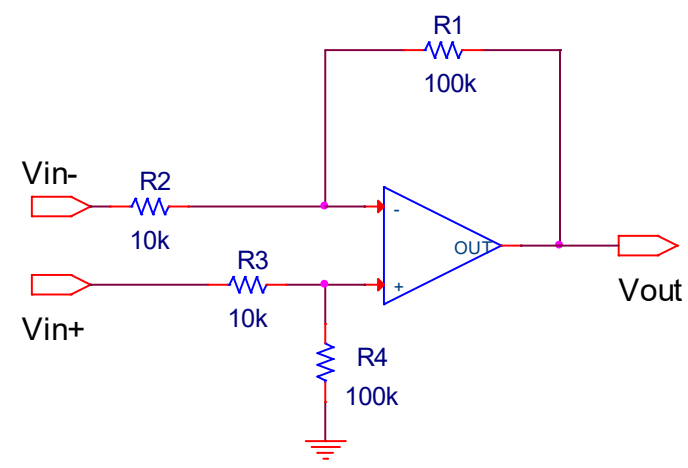

(a)

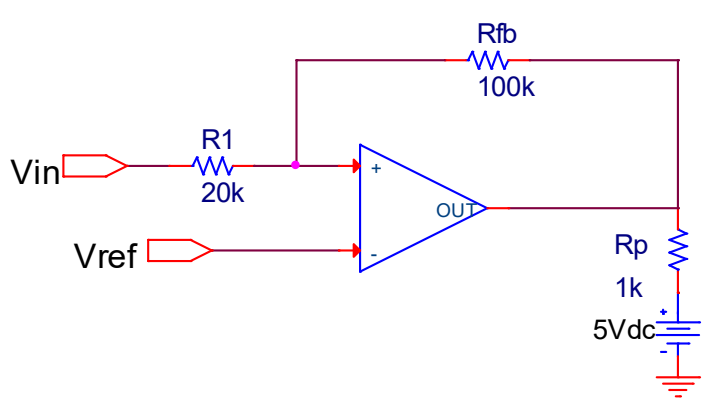

(b)

Figure 2: Circuits analysed for humidity robustness a) differential amplifier b) non-inverting comparator.

A non-inverting comparator is used to detect a specific level on a sensed signal like temperature, pressure, current, voltage etc. Figure $2 \mathrm{~b}$ shows the schematic of a non-inverting comparator. It is commonly used in power electronic circuits to detect over-current and over-temperature conditions. The output of the comparator could be used to disable the highcurrent flow in the circuit, thus protecting the device. The non-inverting comparator has two main properties - the upper tripping point (UTP) and lower tripping point (LTP). When input is above the UTP, output of the comparator is a logichigh and when below LTP, the output is a logic-low. The LTP and UTP of the non-inverting comparator in figure $2 b$ is $2 \mathrm{~V}$ and $3 \mathrm{~V}$, respectively.

According to the methodology used in this paper, the water layer was modelled as a resistance across two nodes of the circuit with properties defined by the SIR data from humidity experiments. Applying this methodology to the circuit of differential amplifier of figure $2 \mathrm{a}$ with water layer assumed to form across $\mathrm{R} 1$, the equivalent circuit for analysing humidity robustness becomes the one shown in figure 3 .

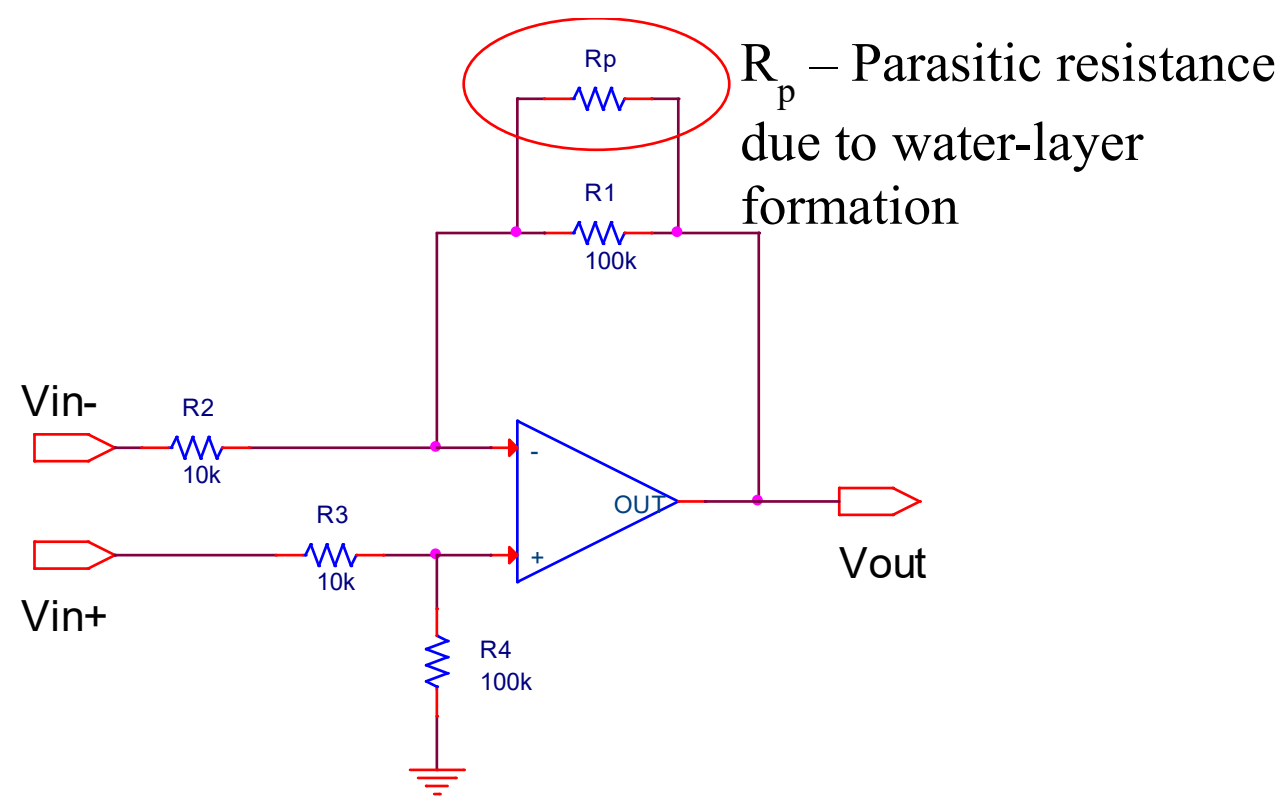

Figure 3: Model of water layer formation across resistor R1 of differential amplifier

When the RH of the ambient climate in which the circuit operates changes properties of the water on the PCB also changes according to the experimental data from humidity experiments. So, the value of Rp in figure 3 is a variable with respect to ambient RH. Similar logic applies to the effect of contamination surface concentration on Rp. The following sub-sections discuss in detail the effect of humidity and contamination on the sensitivity of differential amplifier and noninverting comparator circuits. Orcad Capture CIS was used in this work for circuit simulation. 
To simulate the effects of humidity and contamination, a differential sine voltage of $0.1 \mathrm{~V}$ and $1 \mathrm{kHz}$ a.c is applied across the terminals Vin+ and Vin- of the differential amplifier circuit shown in figure 2a. The nominal output of the circuit in figure 3 for the above mentioned input is a sine wave of $1 \mathrm{~V}$ in amplitude, corresponding to the gain of 10 . When water layer forms across a resistance, the net resistance of the parallel combination with the parasitic resistance Rp due to the water layer is lower than the individual resistances. So, if water layer forms across R1 or R4 the effect would be to reduce the gain ' $G$ ' according to equation 2 . But if the water layer is across R2 or R3 the gain would increase.

To study effect of humidity and contamination on a non-inverting comparator, the water layer is assumed to form on resistors $\mathrm{Rfb}$ and $\mathrm{R} 1$ of figure $2 \mathrm{~b}$. A $5 \mathrm{~V}$ peak-to-peak amplitude sine wave of $1 \mathrm{kHz}$ frequency and $2.5 \mathrm{~V}$ d.c offset is applied as the input.

\subsection{Humidity robustness of differential amplifier circuit}

The effect of humidity and contamination on the functionality of differential amplifier is simulated assuming water layer formation across the terminals of one component only at a time. With this assumption the differential amplifier circuit is simulated for humidity and contamination effects on resistors R1 and R2. Figures $4 \mathrm{a}$ and $4 \mathrm{~b}$ show the variation in differential gain for different climatic conditions of RH and DL-Malic acid for the components R1 and R2 in the circuit of figure $2 \mathrm{a}$.

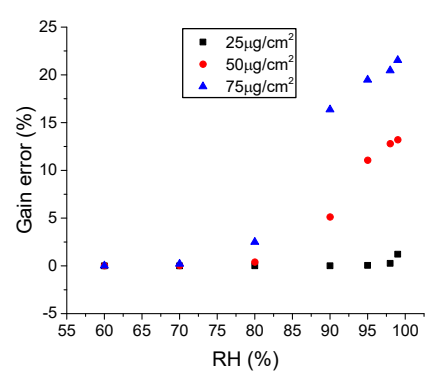

(a)

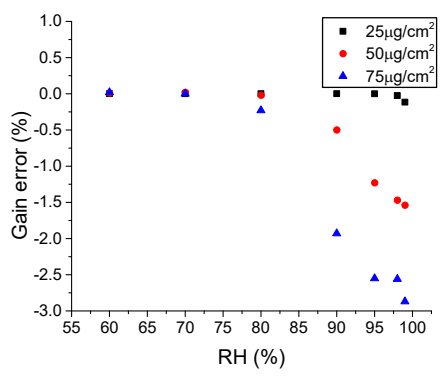

(b)

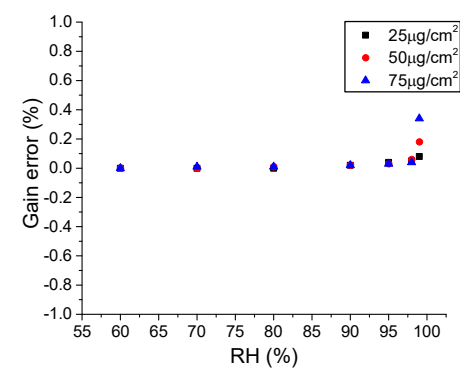

(c)

Figure 4: Variation in 'G' for effect of a) DL-Malic as residue on R1 b)DL-Malic as residue on R2 and c) adipic acid as residue on $\mathrm{R} 1$ with $0.1 \mathrm{~V}, 1 \mathrm{kHz}$ sine wave electrical input and $25^{\circ} \mathrm{C}$

It is seen from figures $4 \mathrm{a}$ and $4 \mathrm{~b}$ that the absolute value of error in gain increases with increasing RH. For DL-Malic acid, which represents residue from an aggressive no-clean flux system, the error increased drastically beyond $80 \%$, which is the DRH for DL-Malic acid. The error in the gain was only $2.5 \%$ below $80 \% \mathrm{RH}$ and $75 \mu \mathrm{g} / \mathrm{cm}^{2}$ WOA surface concentration. The error increased steadily for RH above $80 \%$ which is the DRH of DL-Malic acid. The error reached $25 \%$ for $99 \%$ RH at $75 \mu \mathrm{g} / \mathrm{cm}^{2}$ of DL-Malic acid. The sudden increase in error above DRH is because of a thicker water layer formation due to deliquescence[21]. For surface concentration of $50 \mu \mathrm{g} / \mathrm{cm}^{2}$ the trend in gain error with RH was similar to that for $75 \mu \mathrm{g} / \mathrm{cm}^{2}$. For $25 \mu \mathrm{g} / \mathrm{cm}^{2}$ the error in gain was found to be negligible showing that the reduction in SIR is not significant for interfering with the circuit.

The error in gain with adipic acid as contamination as shown in $4 \mathrm{c}$ was negligible compared to that of DL-Malic acid. This shows that circuits manufactured with adipic acid based no-clean solder fluxes expected to perform more reliably compared to DL-Malic acid based solder fluxes in humid climatic conditions.

The other resistances in the circuit of figure 3 did not cause as much error as that of R1. This is because the sensitivity of gain is dependent on the resistances, in this particular case of the differential amplifier R1 being the most sensitive.

\subsection{Humidity robustness of Non-inverting comparator circuit}

Figures $5 \mathrm{a}$ and $5 \mathrm{~b}$ shows the effect of humidity on LTP and UTP due to water layer formation on resistor Rfb, when DLMalic acid is used as contamination. Figures $6 \mathrm{a}$ and $6 \mathrm{~b}$ shows the effect of humidity on LTP and UTP due to water layer formation on resistor R1, when malic acid is used as flux. 


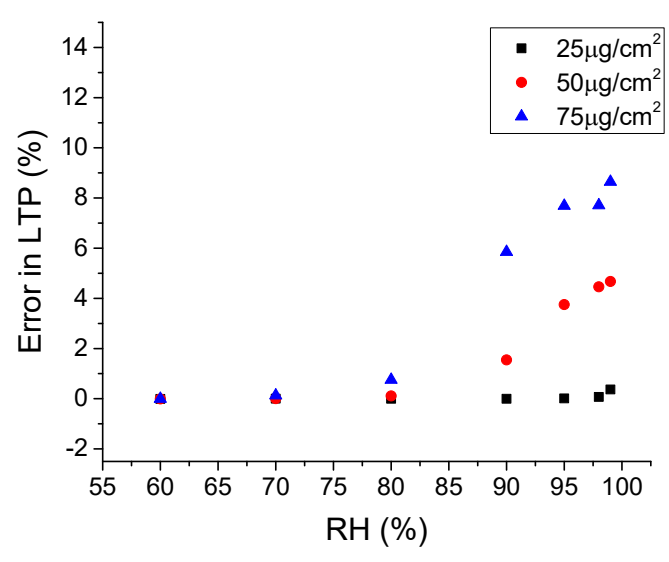

(a)

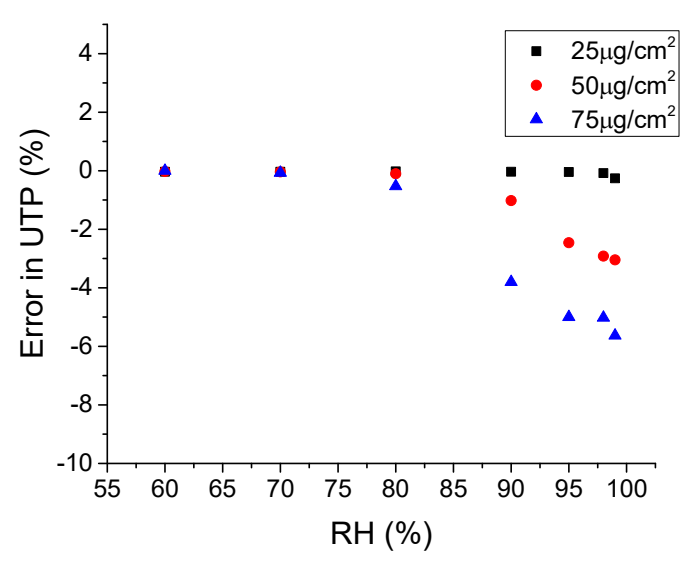

(b)

Figure 5: Effect of humidity and malic acid on Rfb - a) variation in LTP b) variation in UTP for $1 \mathrm{kHz}$ sine wave electrical input and $25^{\circ} \mathrm{C}$

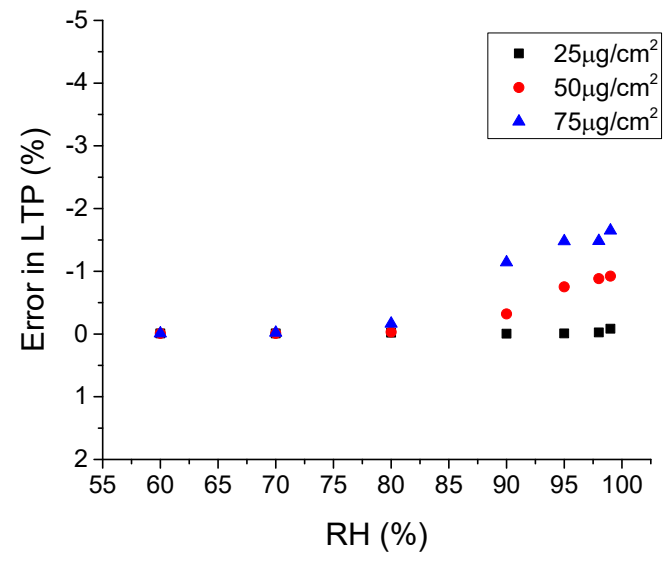

(a)

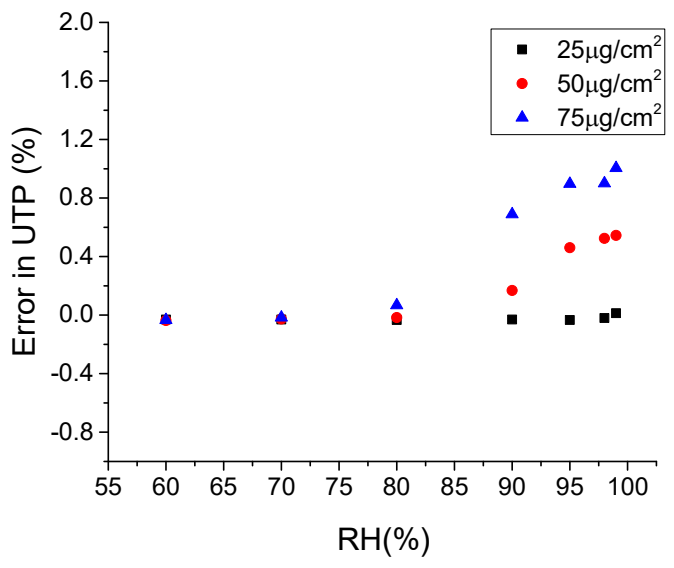

(b)

Figure 6: Effect of humidity and malic acid on R1 - a) variation in LTP b) variation in UTP for $1 \mathrm{kHz}$ sine wave electrical input and $25^{\circ} \mathrm{C}$

Analysis of the comparator also shows that the absolute value of error increases with increasing RH and surface contamination concentration. The highest error in LTP and UTP are obtained when DL-Malic acid was used as contamination. The highest error in LTP is $10 \%$ when 'Rfb' gets affected by humidity and DL-Malic acid concentration was $75 \mu \mathrm{g} / \mathrm{cm}^{2}$. The maximum error in UTP for Rfb under similar conditions was $6 \%$. When R1 gets affected by humidity and contamination, the highest error in LTP was $2 \%$ and UTP was $1.2 \%$ both for $75 \mu \mathrm{g} / \mathrm{cm}^{2}$ of DL-Malic acid. For $50 \mu \mathrm{g} / \mathrm{cm}^{2}$ and $25 \mu \mathrm{g} / \mathrm{cm}^{2}$ of DL-Malic acid, the error is lower compared to $75 \mu \mathrm{g} / \mathrm{cm}^{2}$. The error increases with RH for all three values of surface concentrations. The error in LTP and UTP for both resistors with adipic acid as contamination was negligible as shown in figures 7 and 8 . 


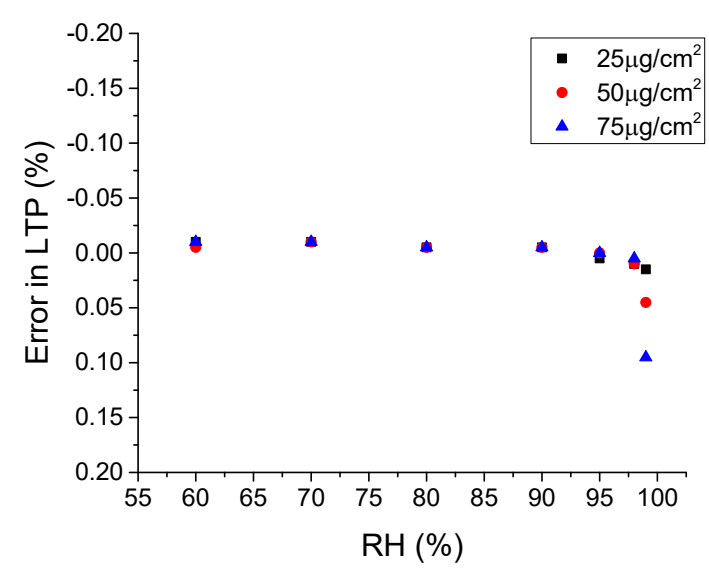

(a)

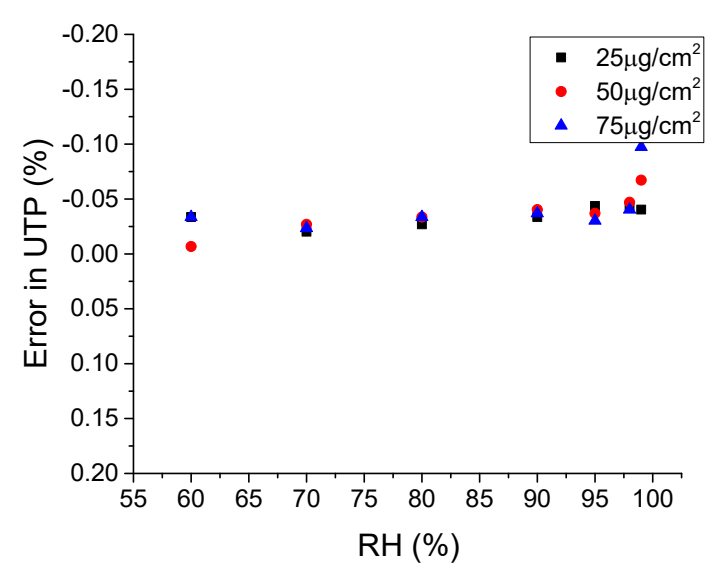

(b)

Figure 7: Effect of humidity and adipic acid on Rfb - a) variation in LTP b) variation in UTP for $1 \mathrm{kHz}$ sine wave electrical input and $25^{\circ} \mathrm{C}$

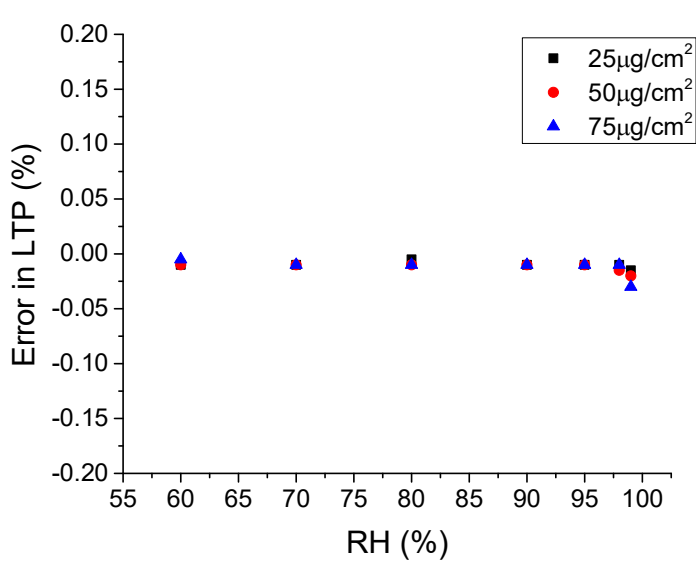

(a)

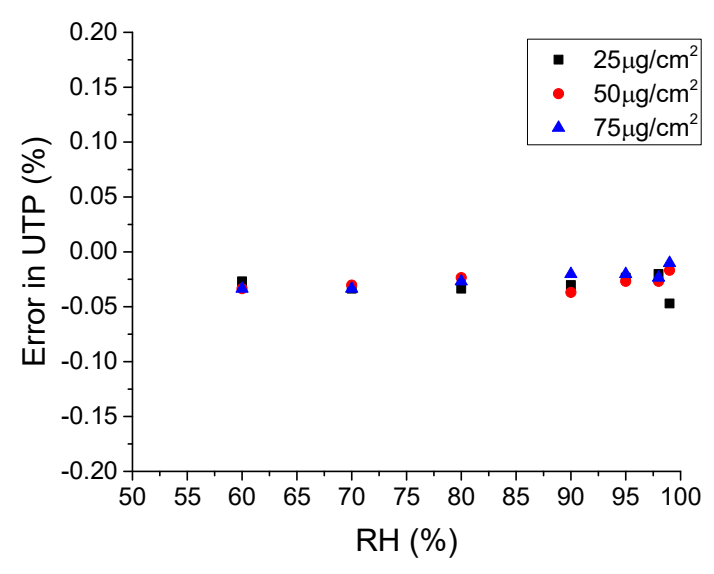

(b)

Figure 8: Effect of humidity and adipic acid on R1 - a) variation in LTP b) variation in UTP for $1 \mathrm{kHz}$ sine wave electrical input and $25^{\circ} \mathrm{C}$

\subsection{Effect of contamination type on humidity robustness}

An implication of the analysis of differential amplifier and non-inverting comparator with adipic and DL-Malic acids as contamination is that PCBs assembled with solder fluxes where adipic acid is the main constituent WOA would not cause severe failures due to humidity. On the other hand, solder fluxes with DL-Malic acid as WOA would cause upto a $25 \%$ error in gain for the differential amplifier when the humidity is above $80 \% \mathrm{RH}$. Even though the acceptability of error in circuit performance characteristics like gain depends on the application, a $25 \%$ error in gain would be unacceptable in any application.

From the analysis of the two above circuits, adipic acid performs better compared to DL-Malic acid in presence of humidity. This is because of the high deliquescence $\mathrm{RH}$ of adipic acid $99 \%$ and also its low solubility of $15 \mathrm{~g} / \mathrm{kg}$ in water[21]. Whereas DL-Malic acid exhibits a low DRH of $80 \%$ and higher solubility of $1400 \mathrm{~g} / \mathrm{kg}$ of water[21]. High DRH of the WOA used in solder flux provides greater margin to formation of a thick water layer due to deliquescence. Also, lower solubility translates to lower conductivity of the water layer or higher values of 'Rp' in the equivalent circuit as shown in figure 3, which is favourable from a humidity related reliability perspective. So by choosing the proper WOA based solder-flux in the component assembly process the effects of humidity could be minimised to a great extent.

The methodology demonstrated in this paper to simulate humidity and contamination related effects on electronics used leakage-current data where a single WOA was the surface contamination. But, commercially available solder fluxes have multiple WOAs as activators. Solder fluxes also contain vehicle, solvent and additive components[28] which may have an effect on the formation of water layer on PCBs. More research can be done to study the correlation between data 
from single and multiple WOA and also the data from actual commercially available solder fluxes. The leakagecurrent/SIR data could be implemented as a library in circuit simulators to simulate the effects of humidity and contamination.

Another way to minimise the effects of humidity and contamination is to incorporate modifications in the cirucit design itself so that the circuit becomes more fault-tolerant. The following section demonstrate based on the above analysis, how one could improve the humidity robustness by modification of circuits.

\section{Improvements to circuit reliability due to humidity}

An instrumentation amplifier is a modified version of the differential amplifier with better characteristics like higher input impedance and lower output impedance. Figure 9a shows an instrumentation amplifier of gain 10 designed with opamps. The gain ' $G$ ' of the instrumentation amplifier in figure 9 a is given by:

$$
G=(R 2 / R 1) \cdot(1+2 \cdot R 6 / R 5)
$$

The instrumentation amplifier uses more components compared to a differential amplifier with the advantage of better input and output impedances.

Similar to a non-inverting comparator, an inverting comparator is also used to detect a specific level on a sensed signal like temperature, pressure current, voltage etc. But unlike the non-inverting comparator, for an inverting comparator, output of the comparator is a logic-low when input is above the upper threshold and a logic-high when below lower threshold. Figure 10a shows an inverting comparator configuration.

The following subsections compares the functionalities of instrumentation amplifier with the differential amplier and inverting with non-inverting comparator. Also analysed is the effect of splitting a high-value resistor into multiple resistances and related humidity responses.

\subsection{Instrumentation amplifier vs differential amplifier}

To relate the performances of differential and instrumentation amplifiers in the presence of humidity and contamination, the errors in gain of both the circuits were compared when humidity and contamination affects the resistances R1 and R6 of differential and instrumentaion amplifiers respectively. The simulated contamination was DL-Malic acid at a surface concentration of $75 \mathrm{ug} / \mathrm{cm}^{2}$. The same $0.1 \mathrm{~V}, 1 \mathrm{kHz}$ sine signal applied for differential amplifier is used as the input also for this circuit. Figure 9b shows the comparison of the two circuits, which indicate that the error in gain was similar for both the amplifiers until $80 \% \mathrm{RH}$ which is the deliquescent $\mathrm{RH}$ for malic acid. For RH greater than $80 \%$, instrumentation amplifier shows much less error in gain compared to the differential amplifier. The maximum error shown by instrumentation amplifier was only $6 \%$ whereas for differential amplifier this was near to $25 \%$. This shows that an instrumentation amplifier has higher reliability to humidity and hygroscopic contamination compared to differential amplifier. The instrumentation uses lower value components compared to the differential amplifier to achieve the same value of gain. Effect of humidity on a smaller value resistor is less compared to that of a bigger value resistor due to the formation of parallel equivalent of $\mathrm{Rp}$ with the resistor concerned. Also, since the gain determining parameters are distributed among higher number of resistances for an instrumentation amplifier probability of water film formation on all the resistors at the same time also decreases. Lower value resistances combined with the topology results in better robustness of instrumentation amplifier compared to the differential amplifier. 


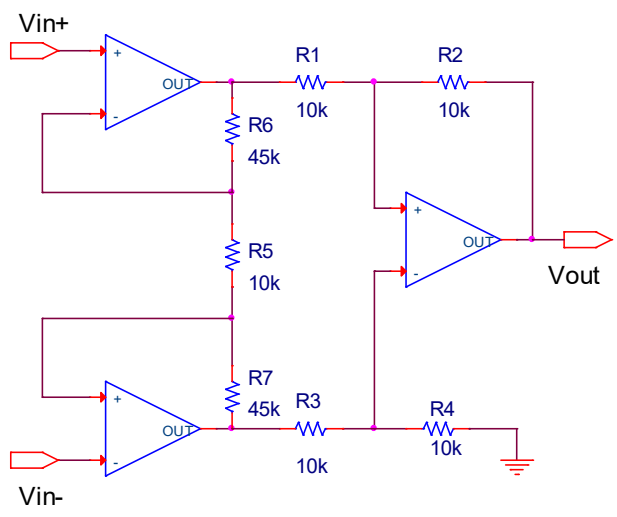

(a)

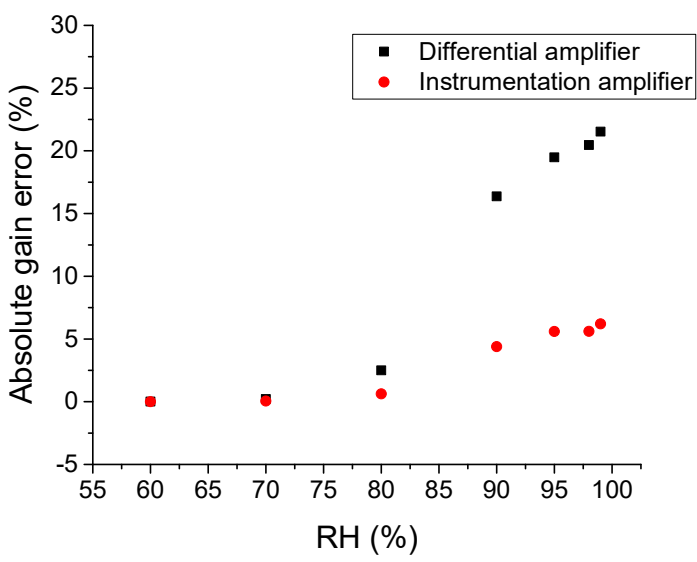

(b)

Figure 9: Comparison of differential and instrumentation amplifiers for effect of humidity - a) Schematic of Instrumentaion amplifier b) Variation in gains of differential and instrumentation amplifiers with $0.1 \mathrm{~V}, 1 \mathrm{kHz}$ sine wave electrical input and $25^{\circ} \mathrm{C}$

But, this improvement in reliability would come at an expense of higher component count. The instrumentation amplifier uses 3 opamps and 7 resistors whereas a differential amplifier uses only 1 opamp and 4 resistors. Hence, the choice to use either a differential or instrumentation amplifier would be based on a trade-off between the degradation in circuit performance and PCB space usage.

\subsection{Inverting comparator vs Non-inverting comparator circuit}

When the non-inverting comparator of figure $2 \mathrm{~b}$ is used for detecting over-currents for circuit protection applications, the $10 \%$ error in LTP during humidity exposure is definitely not acceptable and suitable solutions need to be found to lower the vulnerability of the circuit to humidity-related effects. The inverting comparator could be a suitable alternative to the non-inverting comparator. A comparison is done between the non-inverting type of comparator to the inverting type of comparator. An inverting comparator is designed with the same threshold values as that of the non-inverting comparator. Figure 10b compares both the circuits for their lower threshold voltages when DL-Malic acid at $75 \mu \mathrm{g} / \mathrm{cm}^{2}$ is used as the contamination affecting resistor Rfb in both circuits. Negligible difference was noticed in the effect of humidity and contamination on upper threshold of both comparator configurations.

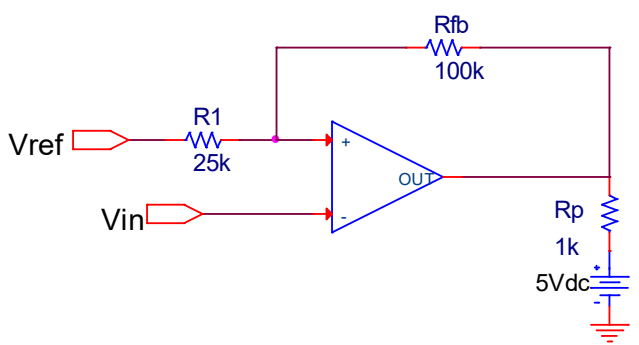

(a)

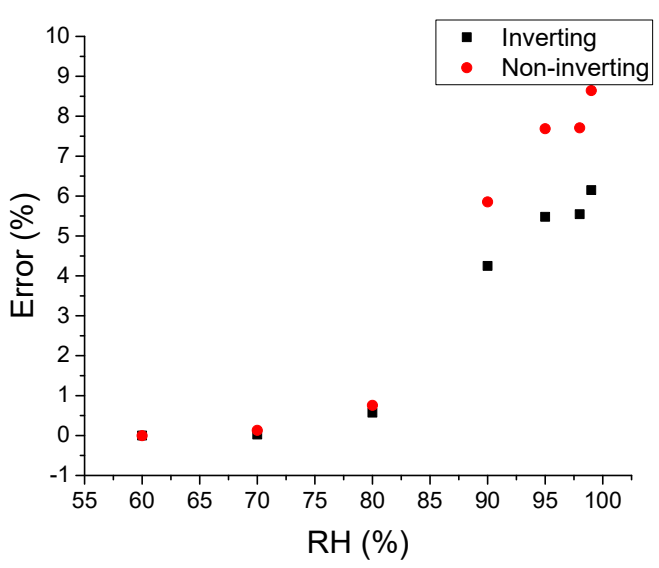

(b)

Figure 10: a) Inverting comparator b) Comparison of LTP for inverting and non-inverting comparators for $1 \mathrm{kHz}$ sine wave electrical input and $25^{\circ} \mathrm{C}$

Figure 10b showed that inverting comparator performs slightly better with lower error of $6 \%$ compared to $9 \%$ for noninverting comparator. This improvement in performance with an inverting comparator could be beneficial depending on 
the application. Since same value components were used for both inverting and non-inverting comparators, the higher robustness of the inverting configuration is solely due to the difference in the circuit topology.

\subsection{Higher humidity robustness by splitting high resistances}

From the analysis of the differential amplifier, it was seen that the most sensitive component was R1. Therefore one solution for improving humditiy robustness is to reduce the sensitivity of the resister for parasitic water film formation acting as parallel resistor. This can be done by splitting the component R1 to multiple components of lower resistance. This will effectively serve two purposes: (i) reduce the sensitivity of each resistor and (ii) making it difficult to form water film on all resistors at the same time. When a resistor is split into multiple resistances the parasitic resistance due water layer $\mathrm{Rp}$ forms across each of the individual resistances. Assuming the same value for $\mathrm{Rp}$ across all the split resistances the net resistances of the network is higher than that with a single high resistance. Figure 11a shows the schematic of a differential amplifier with R1 split into two 50K resistances. Figure $11 \mathrm{~b}$ compares the error in gain with single and split resistances for $75 \mu \mathrm{g} / \mathrm{cm}^{2}$ of DL-Malic acid as contamination.

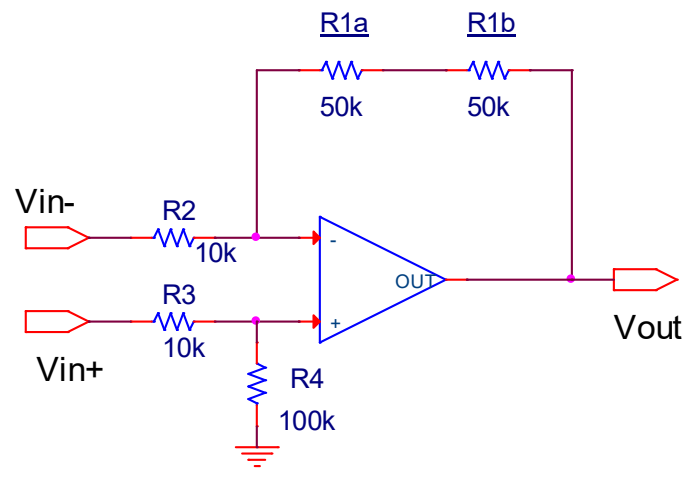

(a)

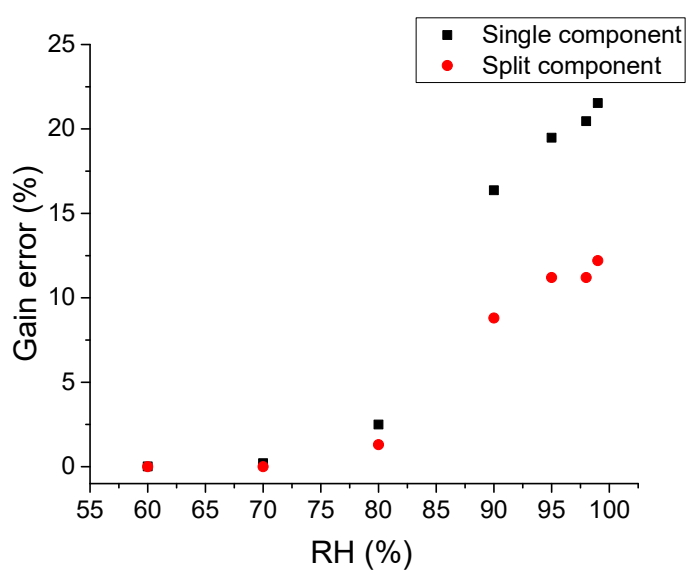

(b)

Figure 11: a) Schematic of differential amplifier with split components b) comparison of error in gain with single and split components with $0.1 \mathrm{~V}, 1 \mathrm{kHz}$ sine wave electrical input and $25^{\circ} \mathrm{C}$

The highest error in the differential amplifier with split components was $14 \%$ compared to $25 \%$ with single resistance for R1. Further improvements in humidity robustness can be achieved by splitting resistor further in this case or on any circuit when there is a critical component. The acceptability of the decrease in error and the number of components to which a resistance is split into is a trade-off that should be decided during the design-phase of the circuit.

\section{Summary}

This work has demonstrated simulation of robustness degradation of electronic circuits due to humidity and surface contamination using experimental leakage-current data. The leakage-current data extracted was for two WOAs which are used as activators in the no-clean flux systems namely - adipic and DL-Malic acid on a standard SIR pattern. The reliability of the circuits analysed decreased with increasing RH and decreased rapidly beyond DRH of the WOA used in the solder flux. The reliability of electronic circuits to humidity and contamination can be significantly improved by the right choice of solder flux and the circuit configuration. A simulation of the effect of using various solder fluxes on circuits can be done in the design phase of the product itself by using the methodology presented here. The simulation can help in choosing the right solder flux and make suitable circuit modifications to improve reliability. If the reliability target cannot be met by the above, then accumulation of high humidity itself should be prevented by humidity control techniques or by use of conformal coatings. The methodology demonstrated in this work can be incorporated into circuit simulation software packages to predict reliability of electronic circuits towards humidity and contamination in the design phase of the product itself. 


\section{Acknowledgement}

This research was conducted as part of the IN SPE project funded by Innovation Fund Denmark and CELCORR(www.celcorr.com). The authors would like to acknowledge the funding and help received from the consortium partners.

\section{References}

[1] V. Smet, F. Forest, J. Huselstein, F. Richardeau, Z. Khatir, S. Lefebvre, M. Berkani, ”Ageing and failure modes of IGBT modules in high temperature power cycling”, IEEE Trans. Ind. Elec., vol. 58, no. 10, pp. 4931-4941, October 2011.

[2] R. M. Nelms et al. "200C operation of a $500 \mathrm{~W}$ dc-dc converter utilizing power MOSFETs," IEEE Trans. Industry Applications, Vol. 33, No. 5, pp. 1267-1272, Sept./Oct. 1997.

[3] S. J. Krumbein, ”Metallic Electromigration Phenomena", IEEE CHMT, pp. 5, March 1988.

[4] R. Hienonen, R. Lahtinen, Corrosion and climatic effects in electronics, VTT Publications, 2000.

[5] C. Hillman, J. Arnold, S. Binfield, and J. Seppi, "Silver and Sulfur: Case Studies, Physics, and Possible Solutions," SMTA International Conference, 2007.

[6] D. Minzari, M. S. Jellesen, P. Moller and R. Ambat, "Morphological study of silver corrosion in highly aggressive sulfur environments," Engineering failure analysis, vol. 18, Issue 8, pp. 2126 - 2136, 2011.

[7] M. Tencer, "Deposition of aerosol ("hygroscopic dust") on electronics - Mechanism and risk," Microelectronics reliability, vol. 48, Issue 8, pp. 584-593, 2008.

[8] R. B. Comizzoli, R. P. Frankenthal, P. C. Milner, J. D. Sinclair,'Corrosion of Electronic Materials and Devices”, Science, Vol. 234, no. 4774 , pp. 340-345, 1986

[9] J. D. Sinclair, L. A. Psota-Kelty, C. J. Weschler and H. C. Shields, " Deposition of Airborne Sulfate, Nitrate, and Chloride Salts as It Relates to Corrosion of Electronics," Journal of electrochemical society, Vol. 137, Issue 4, pp. 1200-1206, 1990.

[10] H. Conseil-Gudla, Z. Staliulionis, M. S. Jellesen, M. Jabbari, J. H. Hattel, R. Ambat, " Humidity build-up in electronic enclosures exposed to constant conditions," IEEE transactions on components packaging and manufacturing technology, vol.7, Issue 3, pp. 412-423, 2017.

[11] H. Conseil, V. C. Gudla, M. S. Jellesen, R. Ambat, Humidity build-up in a typical electronic enclosure exposed to cycling conditions and effect on corrosion reliability, IEEE Transactions on Components, Packaging and Manufacturing Technology, vol. 6, Issue 9, pp. 1379-1388, 2016.

[12] A. W. Adamson, A. P. Gast, Physical chemistry of surfaces, John wiley and sons Inc., 1997.

[13] M. Tencer, Moisture Ingress into Nonhermetic Enclosures and Packages.A Quasi-Steady State Model for Diffusion and Attenuation of Ambient Humidity Variations, Electronic components and technology conference, pp. 196-209, 1994.

[14] J. B. Jacobsen, J. P. Krog, A. H. Holm, L. Rimestad, A. Riis, Climate-Protective Packaging Using Basic Physics to Solve Climatic Challenges for Electronics in Demanding Applications, IEEE Industrial Electronics Magazine, vol. 8, Issue 3, pp. 51-59, 2014.

[15] D. Minzari, M. S. Jellesen, P. Moller and R. Ambat, " On the electrochemical migration of tin in electronics," Corrosion science, Vol. 53, Issue 10, pp. 3366-3379, 2011.

[16] H. Conseil, M. S. Jellesen and R. Ambat, " Printed Circuit Board Surface Finish and Effects of Chloride Contamination, Electric Field, and Humidity on Corrosion Reliability," Journal of electronic materials, Vol. 46, Issue 2, pp. 817-825, 2017.

[17] B.I. Noh, S.B. Jung, "Characteristics of environmental factor for electrochemical migration on printed circuit board", Journal of Materials Science: Materials in Electronics, Vol. 19, Issue 10, pp. 952--956, 2008. 
[18] D.Q. Yu, W. Jillek, E. Schmitt, "Electrochemical migration of lead free solder joints", Journal of Materials Science: Materials in Electronics, Vol. 17, Issue 3, pp 229--241, 2006.

[19] D. Pauls, "Residues in printed wiring boards and assemblies," Circuit World, vol. 27, no. 1, pp. 32-41, Oct. 2000.

[20] H. Conseil, M. S. Jellesen and R. Ambat, " Contamination profile of Printed Circuit Board Assemblies in relation to soldering types and conformal coating," Proceedings of Eurocorr 2014, 2014.

[21] V. Verdingovas, M. S. Jellesen and R. Ambat, "Solder Flux Residues and Humidity-Related Failures in Electronics: Relative Effects of Weak Organic Acids Used in No-Clean Flux Systems," Journal of Electronic Materials, Vol. 44, Issue 4, pp. 1116-1127, 2015.

[22] S. Zhan, M. H. Azarian, M. Pecht, "Surface Insulation Resistance of Conformally Coated Printed Circuit Boards Processed with No-Clean Flux", IEEE Transactions on Electronics Packaging Manufacturing, vol. 29, no. 3, pp. 217-223, July 2006.

[23] L. C. Zou; C. Hunt, "Characterization of the Conduction Mechanisms in Adsorbed Electrolyte Layers on Electronic Boards Using AC Impedance,” Journal of the Electrochemical Society, Vol. 156, Issue 1, pp. C8-C15, 2009.

[24] V. Verdingovas, M. S. Jellesen and R. Ambat, "Relative effect of solder flux chemistry on the humidity related failures in electronics," Soldering and Surface Mount Technology, Vol. 27, Issue 4, pp. 146-156, 2015.

[25] V. Verdingovas, S. Joshy, M. S. Jellesen, R. Ambat, "Analysis of surface insulation resistance related failures in electronics by circuit simulation," Circuit World, Vol. 43, Issue 2, pp. 45-55, 2017.

[26] S. Joshy, V. Verdingovas, M. Jellesen, R. Ambat, "Simulation of electronic circuit sensitivity towards humidity using electrochemical data on water layer", proceeding in 17th Electronics Packaging Technology Conference (EPTC), pp. 1-5, 2015.

[27] V. Verdingovas, M. S. Jellesen, R Ambat, "Impact of NaC1 Contamination and Climatic Conditions on the Reliability of Printed Circuit Board Assemblies", IEEE Transactions on Device and Materials Reliability, vol. 14, no. 1, pp. 42-51, 2014.

[28] M.S. Jellesen, D. Minzari, U. Rathinavelu, P. Moller, R. Ambat, " Corrosion failure due to flux residues in an electronic add-on device", Engineering failure analysis", Vol. 17, Issue 6, pp. 1263-1272, 2010. 